\title{
The structural configurations of root categorization ${ }^{1}$
}

\author{
Artemis Alexiadou ${ }^{1} \&$ Terje Lohndal ${ }^{2,3}$ \\ Humboldt Universität zu Berlin ${ }^{1}$ \\ Norwegian University of Science and Technology ${ }^{2}$ \\ UiT The Arctic University of Norway ${ }^{3}$
}

\section{Abstract}

This paper discusses the syntax of roots by way of looking at four different views discussed in the literature: (i) roots merged as complements, (ii) roots merged as modifiers, (iii) roots merged either as complements or as modifiers, and (iv) roots merged in a unique way. A lot of time is devoted to (i) and to demonstrate empirical challenges from both the nominal and the verbal domain. With the exception of (iii), the other views entail that roots are introduced into the structure in a uniform way, which is argued to be advantageous. The four different views are all discussed in detail, though the paper argues that it is hard to find solid evidence that solves the question of how roots are introduced into (morpho-)syntactic representations.

\section{Introduction}

Researchers within Distributed Morphology claim that the units of word formation consist of roots, which combine with elements of the functional vocabulary to form larger units. These roots are acategorial and need to be categorized by functional elements (Marantz 1997, Alexiadou 2009, Arad 2003, 2005, Embick and Marantz 2008, Embick 2010, De Belder 2011,

\footnotetext{
${ }^{1}$ We are grateful to Hans Petter Helland, the audience at the Workshop Roots and Labels in Marburg in March 2014, the participants in the Research Seminar at the University of Stuttgart, the research group EXOGRAM in Trondheim, an anonymous reviewer and the editors of this volume for their comments and suggestions. Alexiadou's research was supported by a DFG grant to the project B6 of the Collaborative Research Center 732 Incremental Specification in Context at the University of Stuttgart.
} 
2013 and others). ${ }^{2}$ An example is provided in (1) where the root is either categorized as a verb (1a) or as a noun (1b).

(1)
a. $[\mathrm{v} v \sqrt{ } \mathrm{ROOT}]$
b. $[\mathrm{n} n \sqrt{\mathrm{ROOT}}]$

Essentially, word formation is syntactic and there are atomic, non-decomposable elements called roots (see also Pesetsky 1995, Borer 2005a, b, 2013). An important question concerns the phrase structural configuration in which a root is inserted. Are roots complements, modifiers, both, or do they enter into a unique relationship unlike all other constituents? In this paper, we will discuss and evaluate these options.

The structure is as follows. In section 2, we will outline the major issues concerning the locus of where and how a root is merged into a syntactic structure. Section 3 is a lengthy discussion of the view that roots can serve as complements, including an extensive critique of that idea. Section 4 presents the proposal that roots are adjoined to their categorizing head, whereas section 5 introduces a compromise suggestion: Roots can either serve as complements or be adjoined. In section 6, we present a view according to which roots are special in the sense that they have a distinguished phrase-structural position. Section 7 offers a discussion of the various alternatives that we have presented and which alternative we favor. Lastly, we summarize the paper in section 8.

\section{The locus of root-merger}

\footnotetext{
${ }^{2}$ The idea that roots are the basic units of word formation is also adopted by exoskeletal approaches (e.g. Borer 2005a, b, 2013, Grimstad, Lohndal \& Åfarli 2014, Lohndal 2014), though Borer explicitly rejects the categorization assumption adopted in Distributed Morphology.
} 
A common assumption within the Minimalist Program (Chomsky 1995) is that the syntactic operation Merge combines two syntactic objects $\alpha$ and $\beta$ into the unordered set $\{\alpha, \beta\}{ }^{3}$ Typically one of the objects projects and provides the label for the phrasal element (Chomsky 1995).
a. $\quad\{\alpha,\{\alpha, \beta\}\}$
b. $\quad\{\beta,\{\alpha, \beta\}\}$

As this example demonstrates, either $\alpha$ or $\beta$ projects; there are no phrase structure constraints on which element can project. The element that projects will become the head of the given phrase, but both headedness and phrasal status are configurational properties: $\alpha$ or $\beta$ becomes a head or a phrase by virtue of their syntactic positions (Chomsky 1995). Let us briefly consider one implementation of this general idea. Chomsky (1995: 245) argues that "we understand a terminal element LI to be an item selected from the numeration, with no parts (other than features) relevant to $\mathrm{C}_{\mathrm{HL}}$. A category $\mathrm{X}^{\mathrm{min}}$ is a terminal element, with no categorical parts. We restrict the term head to terminal elements". The following definitions of maximal and minimal projections are provided.

(3) a. Maximal projection:

A maximal projection is a syntactic object that does not project any further.

b. Minimal projection:

A minimal projection is a lexical item selected from the numeration

This implies "[...] that an item can be both an $X^{0}$ and an XP" (Chomsky 1995: 249), of which Chomsky mentions clitics as an example.

\footnotetext{
${ }^{3}$ See Zwart $(2009 a, 2009 b, 2011)$ for an alternative in which the set is ordered.
} 
As mentioned in the introduction, frameworks that adopts roots, such as Distributed Morphology (henceforth, DM), assume that roots are categorized syntactically. Examples of the three major lexical categories are provided in (4).

(4)

a.

vP

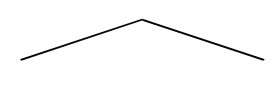

$\mathrm{V}$

$\sqrt{ }$ ROOT

(a)

c.

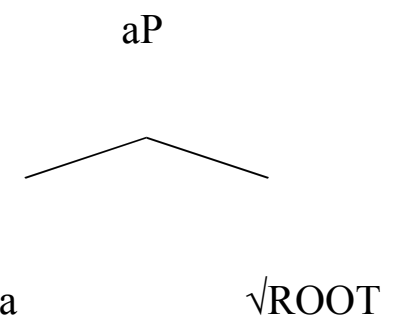

$\sqrt{ }$ ROOT b. $\mathrm{nP}$

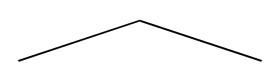

$\mathrm{n}$

$\sqrt{ }$ ROOT

Importantly, in this theory, roots are category neutral. They enter the syntactic derivation without a category and are only categorized by combining with category-defining functional heads/labels.

When roots merge with a categorizer, the categorizer seems to project. ${ }^{4}$ This accounts for the fact that for during the rest of the derivation, the root is categorized as a particular category. Put differently, the configuration in $(5 a)$ is rather common whereas $(5 b)$ does not seem to obtain.

\footnotetext{
${ }^{4}$ Naturally, one can assume that some roots must not project, see Bauke \& Roeper (this volume) for discussion. We will not consider this option here, and refer the reader to the above contribution for detailed discussion.
} 
An implicit assumption in (5) is that the categorizer is always a head. That raises the question: What blocks the structure in $(5 b)$ and should it be blocked?

Despite the wide adoption of roots, the phrase-structure domains of categorization still have not been properly defined. For discussion, see Harley (2005b), Embick (2010), De Belder and van Craenenbroeck (2015), Anagnostopoulou \& Samioti (2014), and to some extent Acquaviva (2009). Various views have been pursued with respect to the question of how roots are merged in morphosyntactic representations. We identify the following alternatives discussed in the literature:

(6) a. Roots are merged as complements of v (e.g., Bobaljik and Harley 2013, Harley 2014 and literature cited there).

b. Roots are merged as v modifiers (Marantz 2013).

c. Some roots are merged as v's modifier while others as v's complement (Embick 2004, 2010, Alexiadou \& Anagnostopoulou 2013)

d. Roots are inserted post-syntactically, thus they cannot take any complements or modify v (de Belder and van Craenenbroeck 2015).

In the following sections, we will discuss these four alternatives in the order in which they appear in (6).

\section{Roots as complements}


In a lot of analyses (see e.g., Embick 2010 and Harley 2014 for discussion), it is often assumed that roots can take complements. A verbal structure would for example have the following structure.

(7)

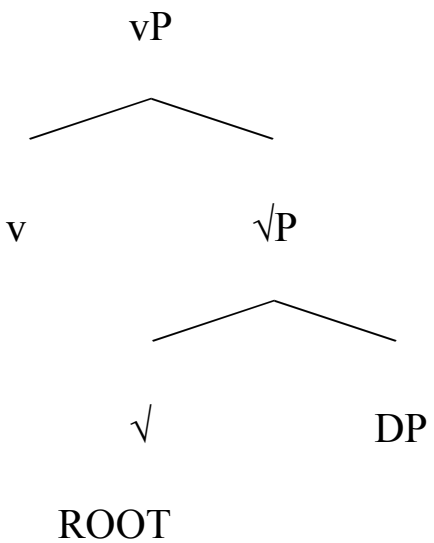

This is a way of re-casting Kratzer's (1996) claim that the internal argument is much closer to the verb than the external argument. More recently, Harley (2014) presents several arguments in favor of this claim. We will discuss them based on Alexiadou (2014), which in turn was based on an earlier incarnation of the present paper. The first concerns one-replacement (3.1), the second verb-object idioms (3.2), and the third root suppletion in Hiaki (3.3). Then we will turn to nominalizations and argue that the relevant data provide no argument in favor of roots being able to take complements (3.4). Then we summarize this long section (3.5).

\subsection{One-replacement}

As has been known since Jackendoff (1977), arguments that are selected cannot be stranded under one-replacement whereas nominal adjuncts allow for stranding.

(8) a. *the student of chemistry and the one of physics.

b. $\quad$ the student with long hair and the one with short hair 
Jackendoff's analysis was that one targets N', an analysis that cannot be implemented in Bare Phrase Structure (Speas 1990, Chomsky 1995, Lohndal 2012). Harley (2005b) illustrates how this phenomenon can be captured without generating problems for Bare Phrase Structure, given that Bare Phrase Structure does not allow for rules to target bar-level projections.

Harley makes the following assumptions: i) verbal study and nominal student both share the same root stud-, ii) the argument is a sister of the root itself, iii) nominalization involves the addition of $\mathrm{n}(-e n t)$, iv) adjunct PPs adjoin to $\mathrm{nP}$, not to $\sqrt{\mathrm{P}}$. This allows her to characterize one-replacement as follows: one is an $\mathrm{nP}$ anaphor, not a $\sqrt{\mathrm{P}}$ anaphor. Harley gives the following structures for student of chemistry and student with long hair. The root head moves to the $n$ head.

(9) the student of chemistry

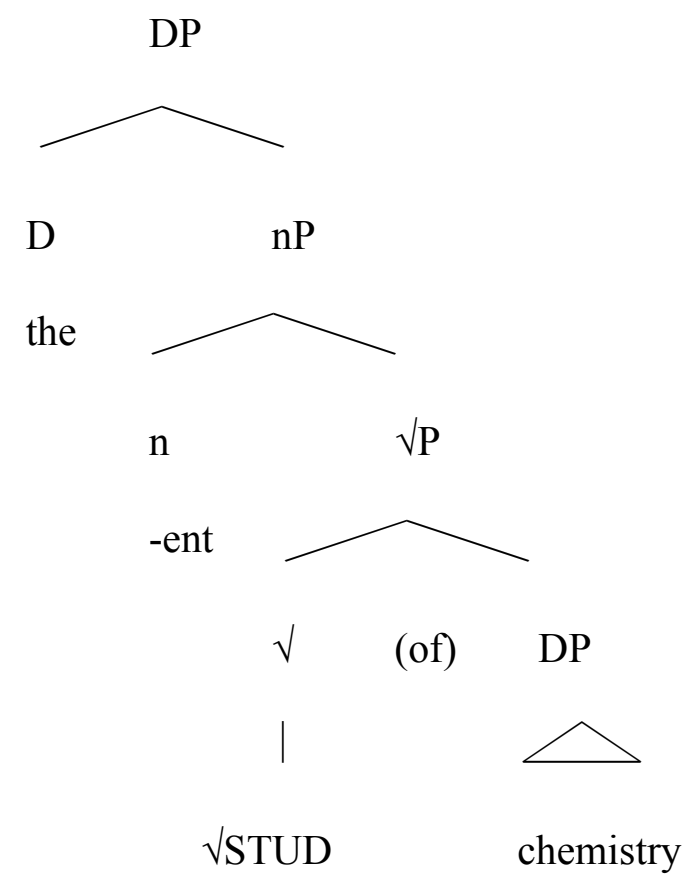

(10) the student with long hair 


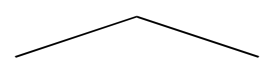

$\mathrm{D} \quad \mathrm{nP}$

the

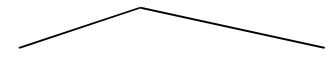

$\mathrm{nP}$

PP
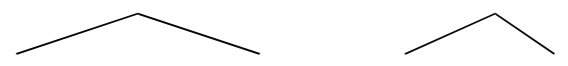

n $\quad \sqrt{ } \mathrm{P} \quad \mathrm{P} \quad \mathrm{DP}$

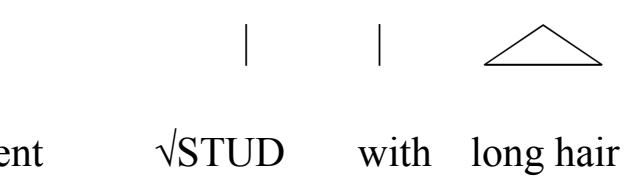

Harley sketches an alternative analysis briefly outlined in note 22 , following a suggestion by a reviewer. We will elaborate on this suggestion here. If we assume, as is done in much of the recent literature (see Alexiadou, Haegeman and Stavrou 2007 for discussion), that the nominal phrase contains a rich array of functional projections, then one replacement can target a layer higher than nP. Specifically, we can assume, following Borer (2005a) and Alexiadou \& Gengel (2011), that one targets the projection CLP, the Classifier Phrase. In Borer's (2005a) framework, the following two functional projections between the DP and the $\mathrm{nP}$ are assumed: (i) the quantity phrase (\#P in her system; similar but not equal to NumberP) and the Classifier Phrase (CLP in her system). All nouns enter the derivation as mass, and become count in the syntax, via CLP.

(11)

DP

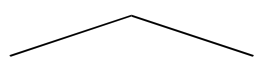

$\mathrm{D} \quad \mathrm{AP} \quad[=$ quantity, hosts numerals/quantifiers $]$

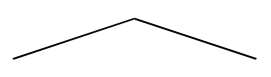




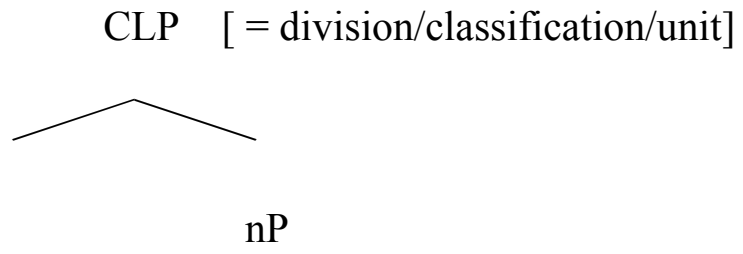

In English, CLP is realized either by the plural marker or the numeral one. For Borer, one is a portmanteau divider/counter, while all other cardinal numerals are solely counters. These two functional projections have different functions. The \#P denotes quantity, and the CLP introduces division, i.e. the function of dividing something. Moreover, the classifier has an individuating function. ClassP is the input to quantity, i.e. if something is divided, it can be counted.

This opens up the possibility that one-replacement targets CLP, and that the adjunct is located above nP, presumably adjoined to CLP. Harley (2014) highlights in her footnote the fact that the selectional restrictions are preserved. However, this has nothing to do with onereplacement. ${ }^{5}$ Student is a deverbal nominal, hence $\mathrm{nP}$ embeds a verbal structure, and in this the introduction of the internal argument takes place pretty much as described above, see Alexiadou (2009), and Borer (2013):

$$
[\mathrm{nP}[\mathrm{vP} \text { theme }[\text { Root }]]]
$$

\footnotetext{
${ }^{5}$ An anonymous reviewer points out that one-replacement must be allowed to cut inside a recursive AP as well as substitute for an entire AP:

(i) $\quad$ a. John has a big blue car and Bill has a small one $=$ small blue car

b. John has a big blue car and Bill has a red one $=$ a red car

We think that such data provide evidence for the view that one replacement targets something higher than the $\mathrm{nP}$. Assuming that adjectives are inserted as adjuncts/specifiers of projections between DP and nP, see Cinque (1994), Alexiadou, Haegeman \& Stavrou (2007) for further references, would be a possible way to explore the size of one-replacement.
} 
3.2. The verb and the direct object

Kratzer (1996) argues that the verb takes a complement but that the subject is severed from the verb both syntactically and semantically (see also Schein 1993). She relies on an argument from Marantz (1984), showing that the verb-object interpretation often receive special/idiomatic meanings, this happens rarely with subject-verb combinations composing with an object (see Nunberg, Sag and Wasow 1994, Horvath and Siloni 2002, Harley and Stone 2013 for much discussion).

(13) a. throw a baseball

b. throw support behind a candidate

c. throw a boxing match (i.e., take a dive)

d. throw a fit

(14) a. take a book from the shelf

b. take a bus to New York

c. take a nap

d. take an aspirin for a cold

e. take a letter in shorthand

(15) a. kill a cockroach

b. kill a conversation

c. kill an evening watching TV

d. kill a bottle (i.e., empty it)

e. kill an audience (i.e., wow them) 
Kratzer argues that the external verb should be severed from the verb's lexical representation.

This will ensure that the external verb cannot yield a special interpretation. That is, instead of (16a) we have (16b).

(16) a. $\quad \lambda y . \lambda x . \lambda e[\operatorname{buying}(e) \& \operatorname{Theme}(\mathrm{x})(\mathrm{e}) \& \operatorname{Agent}(\mathrm{y})(\mathrm{e})]$
b. $\lambda x . \lambda \mathrm{e}[\operatorname{buying}(\mathrm{e}) \& \operatorname{Theme}(\mathrm{x})(\mathrm{e})]$

Since Kratzer's paper, there has been a lot of work on the syntax of external arguments (see, e.g., Hale and Keyser 1993, 2002, Harley 1995, Marantz 1997, Borer 2005a, b, Alexiadou, Anagnostopoulou, and Schäfer 2006, 2015, Folli and Harley 2005, 2007, Jeong 2007, Pylkkänen 2008, Ramchand 2008, Schäfer 2008, 2012, Merchant 2013, Lohndal 2014).

However, Kratzer's argument only goes through if the specification of the verb's meaning only refers to the internal argument, and furthermore, if idiomatic dependencies like these can be captured by defining the meaning of the verb. Kratzer discusses the first premise but not the second. She seems to assume that idiomatic dependencies must be specified over objects in the lexicon, that is, over the verb and its Theme. For reasons of space, we won't discuss these issues here but refer among others to Marantz (1997), Lohndal (2012, 2014), and Anagnostopoulou and Samioti (2014) who all argue that idiomatic dependencies can be defined over outputs of syntax.

In addition, the literature contains various arguments for severing the Theme as well. Lohndal (2014) surveys the following arguments.

(17) a. The semantics of reciprocals such as each other (Schein 2003)

b. Adjectival passives (Borer 2005b)

c. Focus and Neo-Davidsonian representations (Herburger 2000) 

d. Measuring-out Themes (Tenny 1987, 1994; see Borer 2005b)
e. Variable adicities (Borer 2005a, b)

Borer (2005) presents a syntax which completely severs all arguments (see also Lin 2001, Marantz 2005, Bowers 2010, Lohndal 2014). Generalizing the labels somewhat, we get the following structure (Lohndal 2014; see also Alexiadou, Anagnostopoulou and Schäfer 2015).

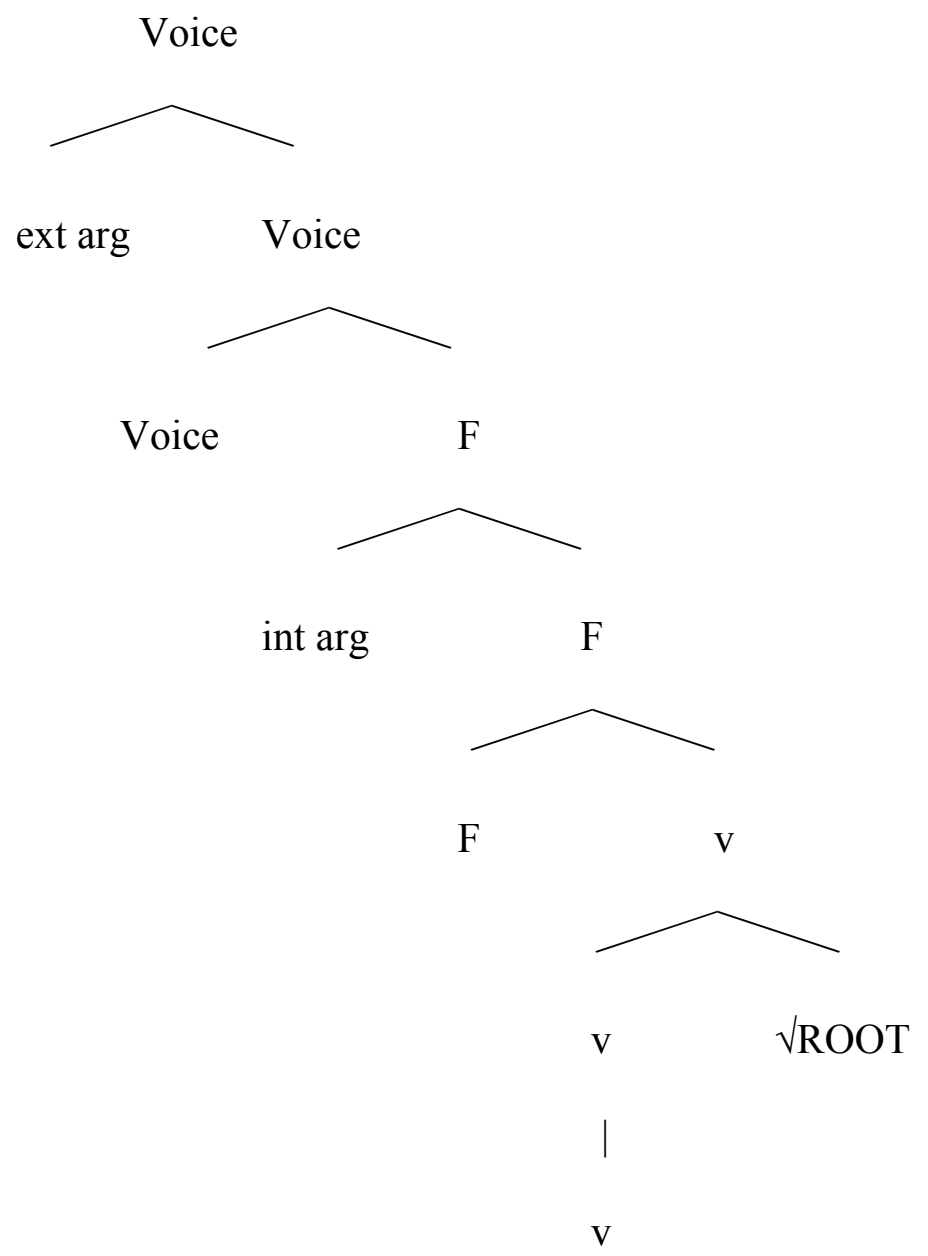

Other alternatives are possible as well (see e.g., Bowers 2010). On this theory, roots are not able to take complements. Rather, the root is merged at the bottom of the structure, and all arguments are merged after the root has been merged. Thus the root does not contribute to building the structure; the structure is built independently of the root. But by inserting the root 
at the bottom, the root is inserted in a verbal structure as opposed to a nominal or adjectival structure, and the F projection takes the $\mathrm{v}$ as its complement, not an $\mathrm{n}$ or a.

\subsection{Suppletion in Hiaki}

Bobaljik and Harley (2013) and Harley (2014) present an argument in favor of roots being able to take complements. The evidence relies on suppletion and is based on data from the Uto-Aztecan language Hiaki.

Suppletion phenomena constitute an area of controversy within Distributed Morphology. The reason is that it is not clear whether suppletion applies to roots as well as the functional vocabulary; see Embick \& Halle (2005). Importantly, however, suppletion is subject to locality effects. The Hiaki data present a puzzle for locality and seem, at first sight, to suggest that suppletion applies both to roots and functional material.

Bobaljik (2012) argues that insertion of suppletive vocabulary items can only be sensitive to features within the same maximal projection, not across a maximal projection boundary.

(19) Locality:

$\alpha$ may condition $\beta$ in (a), not (b):
a. $\quad \alpha \ldots]_{\mathrm{X}}^{0} \ldots \beta$
b. $* \alpha \ldots] \times P \ldots \beta$

Data from Hiaki threaten this generalization. Let us consider the relevant examples.

The number of a subject DP can trigger suppletion in a certain class of intransitive verbs (data from Bobaljik and Harley 2013). 
(20) a. Aapo vuite.

3.SG run.SG

'S/he is running.'

b. Vempo tenne.

3.PL run.PL

'They are running.'

(21) a. Aapo weye.

3.SG walk.SG

'S/he is walking.'

b. Vempo kate

3.PL walk.PL

'They are walking.'

With transitive suppletive verbs, it is the object that triggers suppletion.

(22) a. Aapo/Vempo uka koowi-ta me'a-k.

3.SG/PL the.SG pig-ACC.SG kill.SG-PRF

'He/They killed the pig.'

b. Aapo/Vempo ume kowi-m sua-k.

3.SG/PL the.SG pig-PL kill.PL-PRF

'He/They killed the pigs.'

If this is true subject-verb agreement, this would be a problem for Bobaljik's generalization given that the external argument is merged in a separate projection, as seen above. 
Bobaljik and Harley argue that a plural object DP is base-generated as a sister to the verb root. If the root of the selecting verb is a suppletive root, the two forms will compete for insertion. The object is local enough to condition suppletion.

(23)

$$
\sqrt{P}
$$
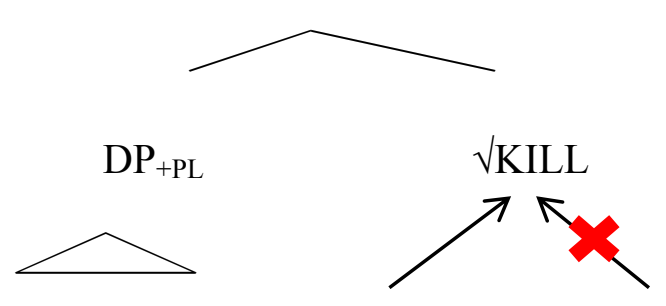

ume toto'im

sua

$*_{m e a}$

the.PL chickens

kill.PL.OBJ

kill.SG.OBJ

If intransitive verbs are unergative, they would constitute a counter-example to (19).

(24)

\section{VoiceP}

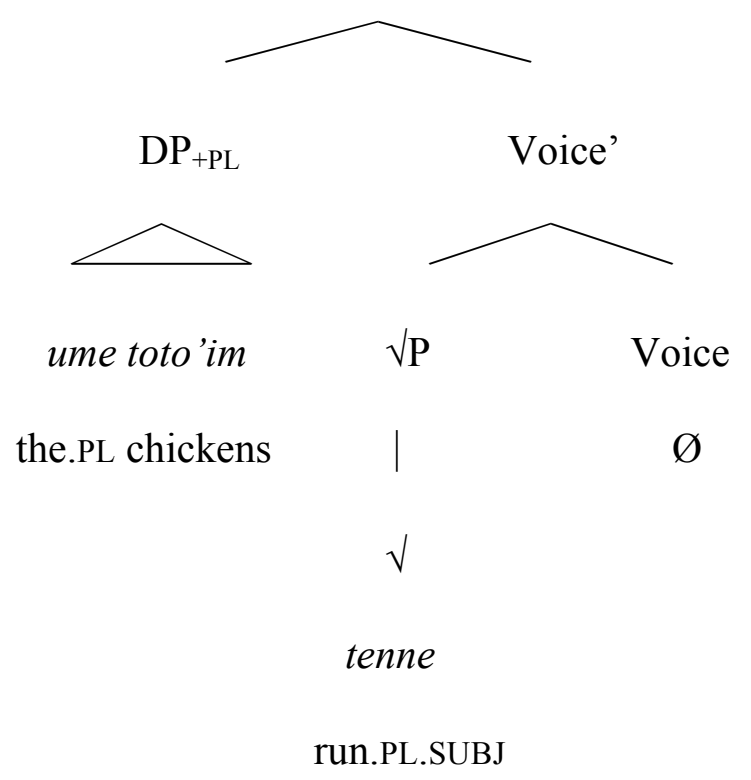


Bobaljik and Harley argue that the intransitive verbs in question indeed are unaccusative. That would pose no problem for (19) as long as roots can take complements as in (23). We assume that their arguments in favor of the unaccusative status are sound.

(19) allows for a specifier within the same projection of a head to condition suppletion. Bobaljik and Harley argue that the definition should be strengthened in order to block specifiers from conditioning suppletion. They suggest (25).

(25) Locality:

$\alpha$ may condition $\beta$ in $(a)$, not (b):
a. $\quad \alpha \ldots]_{\mathrm{X}}^{0} \ldots \beta$
b. $\left.{ }^{*} \alpha \ldots\right] \mathrm{x}^{n} \ldots \beta$, where $\mathrm{n}>0$.

They offer the following motivation (p. 11):

Excluding specifiers from the locality domain of the root also renders moot the possibility that head movement may extend locality domains. Hypothetically, if the root were to undergo head movement to Voice ${ }^{0}$ in [(24)], then - in its derived position - the root would no longer be separated from the external argument by a maximal projection. If not plugged, this could be construed as a loophole that threatens to unravel our account of internal-external argument asymmetries, at least where head movement is involved.

Bobaljik and Harley are essentially postulating a sisterhood condition on suppletion. The root and its conditioning DP have to be sisters at a given point in the derivation. 
However, there are other technical ways of getting around this conclusion. The derivational theory in Lohndal (2014) achieves this result by way of head movement. Lohndal adopts the structure in (26) from Borer (2005a, b), repeated here for expository convenience.

(26)

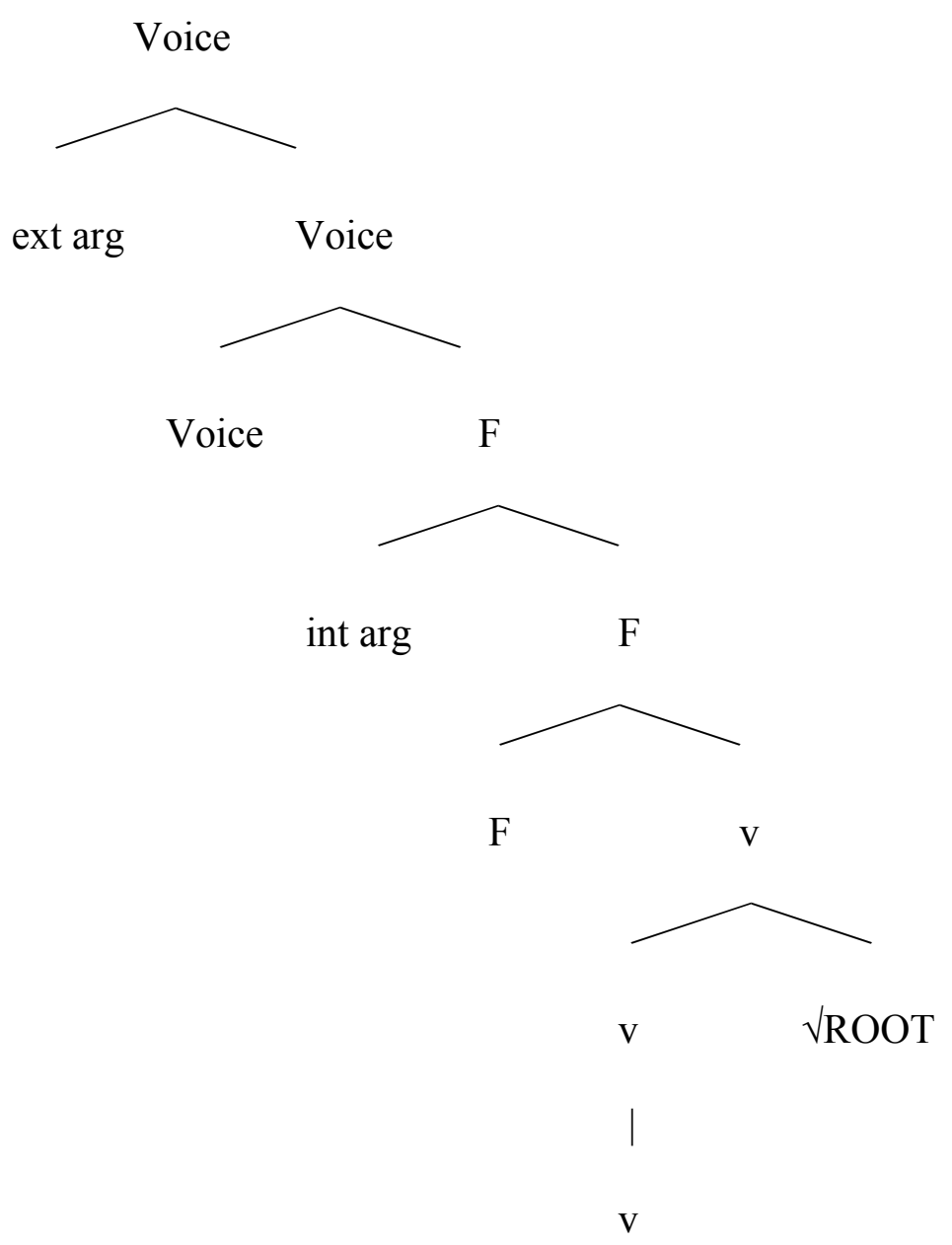

However, he argues that this structure does not exist as a representational object at any point in the derivation. Rather, a head merges with a phrase, whose phrase can then merge with yet a different head. What is not allowed, is for a phrase (e.g., what is depicted as specifiers in (26)) to merge with another phrase. Put differently, at the point in the derivation where the internal argument is to be merged with the FP (consisting of F and its sister vP), a constraint blocking XP-YP merger demands that the complement (YP) of the head is spelled out so that 
the head can merge again with a new phrase (XP). Put simply, a head can only merge with a non-head; two phrases can never merge. ${ }^{6}$

Let us illustrate how this system would apply to the present case. In (26), a copy of the root moves into F (and then into Voice). Various technical implementations are possible; here we assume that the root and F create a complex head. ${ }^{7}$

a.

$$
\mathrm{F}
$$

$\rightarrow$ spell-out $\mathrm{v}(\mathrm{P})$, move $\sqrt{ }$ ROOT to $\mathrm{F}$

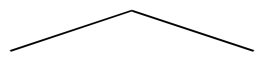

F

$\mathrm{v}(\mathrm{P})$

b.

$\mathrm{F}$

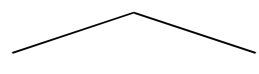

F $\quad \sqrt{ } \quad \sqrt{R O O T}$

c.

$\mathrm{F}$

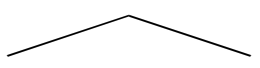

DP $\quad$ F

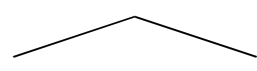

$\mathrm{F}$

$\sqrt{ }$ ROOT

\footnotetext{
${ }^{6}$ See Narita (2014) for a related approach which also bans XP-YP merger.

${ }^{7}$ The structure and derivation are motivated at length in Lohndal (2014), drawing on a range of different data and theoretical arguments. It is impossible to do justice to these arguments in the present paper; see Lohndal's book.
} 
This assumes that the root is "close enough" in (27c) for the DP to condition suppletion. Since F and $\sqrt{ }$ ROOT constitute a complex head, suppletion is possible. ${ }^{8}$ In this system, Bobaljik's (2012) generalization can be maintained, even though the root does not take a complement.

\subsection{No complements of roots appear in a nominal environment}

In the area of nominalizations (see Alexiadou 2010a, $\mathrm{b}$ for general discussion), it has been argued that the Theme can be the complement of the root, viz. Alexiadou (2001) and Embick $(2009,2010)$. If it is true that roots cannot appear with complements, these analyses have to be revised. We argue that the Theme is introduced as the specifier of a functional projection, in line with e.g. Lin (2001), Borer (2005a, b, 2013), Marantz (2005).

Grimshaw (1990) argues in detail that de-verbal nouns do not form a homogeneous class. ${ }^{9}$ They are claimed to be ambiguous between a reading that supports argument structure (AS nominals (ASNs)), and a result/referential (R)-reading that does not. (28a) instantiates the AS-interpretation of the nominal, while (28b) instantiates the R one.
a. the examination of the patients took a long time
b. the examination was on the table
$R$

Table 1 summarizes the criteria Grimshaw introduced to distinguish between the two types of nominals in English (Alexiadou 2009, Borer 2013):

\footnotetext{
${ }^{8}$ There is also the issue of adjacency, in terms of overt string adjacency (Radkevich 2010). (26b) would fulfill that since F is empty. See Embick (2010) and Bobaljik (2012) and the literature cited there for extensive discussion of the importance of adjacency.

${ }^{9}$ Note that Grimshaw actually distinguishes between three classes of nominals: (i) complex event nominals that license AS, (ii) event nominals that do not license AS but still have an eventive interpretation and (iii) result nominals that do not license AS and lack an eventive interpretation.
} 
ASNs

1. Non- $\theta$-assigner, No

$\theta$-assigners, Obligatory arguments

obligatory arguments

2. No event reading

Event reading.

3. No agent-oriented modifiers

Agent-oriented modifiers

4. Subjects are possessives

subjects are arguments

5. by phrases are non-arguments

by phrases are arguments

6. No implicit argument control

Implicit argument control

7. No aspectual modifiers

Aspectual modifiers.

8. Modifiers like frequent, constant only with plural

Modifiers like frequent, constant appear

with singular

9. May be indefinite

Must be definite

10. May be plural

Must be singular

Table 1: R-nominals versus Argument Supporting Nominals

Alexiadou \& Grimshaw (2008) discuss the following observations made in the rich literature on nominalizations:

1) Only nouns which are related to corresponding verbs have argument structure. This means that being associated with an event structure/argument structure is not a property of nouns per se. 
2) Nouns which are identical in form to verbs do not generally behave like ASNs, i.e. they are rigidly different from verbs (recall, offer, report, see (29)). ${ }^{10}$

\section{*The frequent report of looting}

3) -ing nominals are always ASNs. ${ }^{11}$

4) -(a)tion and -ment nominals are frequently ambiguous between ASN and non ASN readings.

On the basis of the above, they propose the following generalization: ${ }^{12}$

\footnotetext{
${ }^{10}$ Newmeyer (2009) reports several zero derived nominals that appear to contradict this claim:

(i) Maria's metamorphosis of the house
}

See Borer (2013) for arguments that most of his cases do not behave as ASNs.

${ }^{11}$ An anonymous reviewer raises the very interesting question of how the formation of idioms relates to this discussion. For instance, the breaking of bread with our friends is ok, while *the playing of ball with friends is not. A detailed discussion of this problem will take us too far afield, but we would like to point out that we take an idiomatic interpretation to be excluded when Voice is present in the structure, see Anagnostopoulou \& Samioti (2014) for arguments from the domain of participles. Alexiadou \& Iordachioaia (2015) discuss cases like the ones mentioned by the reviewer and argue that this suggests that the structures that allow for an idiomatic interpretation exclude Voice.

${ }^{12}$ We take (30) to be understood as referring to event participants. Importantly, (30) raises the question what happens with de-adjectival nominalizations, which seem to license arguments in the absence of a verbal source. Roy (2010) shows, however, that only predicative (intersective) adjectives derive (suffix-based) nominalizations:

(i) $\quad$ a. $\quad$ the poor child
i. the pitiful child
(non-intersective)
ii. the moneyless child
(intersective)

b. This child is poor.

i. $\quad$ \#This child is pitiful. 
(30) Only nouns derived from verbs can have argument structure.

Crucially, then, this means that only those nouns that have a verbal source can appear together with their arguments. Having shown that the arguments of verbs are introduced by functional layers, this leads to the suggestion that the nominal structure embeds a verbal structure that contains the verb's arguments.

We assume, as we did in the previous sections, that the root is introduced at the bottom of the structure, adjoined to a categorizer, e.g., as in (31). This creates a verbal environment, which can then undergo nominalization, see (32b) (the structures are simplified for expository convenience). (32a), the nominal structure that lacks a verbal categorizer, corresponds to the representation of R-nominals in table 1.

$$
\left[\text { FP DP } \text { theme }_{\text {F }} \mathrm{F}[\mathrm{v} \mathrm{v} \sqrt{ } \mathrm{ROOT}]\right.
$$

ii. This child is moneyless.

c. the poverty of the child $\neq$ the pitifulness of the child

In (ic), Roy takes of the child to be the argument of the nominalization, since the adjectival property is predicated of the child:

(ii) the poverty of the child $\quad \Rightarrow \quad$ the child is poor

We follow Roy (2010) and assume that on top of the aP, the nominalization also includes a PredP (see also Bowers 1993) which hosts the argument.

Similar issues arise for of phrases with relational/body part nouns, e.g. the father of John and picture nouns, e.g. the picture of John. We assume that these nouns are not ASNs of the type defined in Grimshaw, i.e. they lack an event structure. We assume that in the case of picture nouns, the possessor is introduced in Spec,nP thus the interpretation of the possessor is rather free. In the case of relational/body part nouns the possessor is introduced as a complement of the noun, see Alexiadou, Haegeman \& Stavrou (2007) for extensive discussion. 
We assume that the various affixes such as -ation, and -ing realize $\mathrm{n}$ in (32):
a. $\quad\left[\mathrm{FP} \mathrm{DP}_{\text {theme }}[\mathrm{F} F[\mathrm{n} \mathrm{n} \sqrt{\mathrm{ROOT}}]\right.$
non- ASNSS
b. $\quad\left[\mathrm{n}\left[(\right.\right.$ Voice $)\left[\mathrm{FP} \mathrm{DP}_{\text {theme }}[\mathrm{F} F[\mathrm{v} \mathrm{V} \sqrt{ }\right.$ ROOT $\left.]]\right]$
$A S N S$

First of all, there is evidence that ASNs may contain F/v: A first piece of evidence in favor of this is the presence of overt verbalizers in English, such as -ify, -ize etc. to which the nominalizing morphology attaches, e.g. modify-modification, hospitalize-hospitalization.

Second, data involving re-prefixation also points to the presence of v. Wechsler (1990) and Marantz (2007) argue that the prefix re- only has a restitutive interpretation and it only attaches to accomplishments, meaning that it needs a state component to modify (von Stechow 1996), i.e. it requires a result state of the type present in (32b). ${ }^{13}$
(33) a. the re-verification of the diagnosis
b. a re-justification of former notations

Thirdly, modification by gradual also points to the presence of v (Borer 2013):
(34) a. Kim's (gradual) formulation of several procedures \{twice/in two weeks
b. Pat's (gradual) formation of many committees \{twice/in two minutes\}

\footnotetext{
${ }^{13}$ As an anonymous rewiever points out, the data involving re-prefixation are more complex, and this is acknowledged in recent work by Lechner, Spathas, Alexiadou \& Anagnostopoulou (2015). For reasons of space we cannot enter a detailed discussion of this complexity. Still, our point is that whatever holds in the verbal domain with respect to re-prefixation also holds in the nominal domain.
} 
c. Robin's (gradual) dissolution of these chemicals \{twice/in two hours\}

Piñon (2000) argues that gradually (and thus, presumably, also gradual with deverbal nouns) involves a change: whatever happens gradually should in fact happen and not just hold. This modifier is sensitive to the type of change characteristic of accomplishments, which involves the presence of $\mathrm{v} / \mathrm{F}$ in our system.

Naturally, the structure of ASNs may be richer, in that it can contain further functional layers associated with verbal clauses. For instance, certain ASNs may contain Voice, Borer (2013), Alexiadou (2001, 2009), Alexiadou, Iordachioia, Cano, Martin \& Schäfer (2014). Evidence for this comes from the following observations:

a) they allow by-phrases: the destroying of the city by the enemy

b) As has been discussed in the literature, ing-of gerunds (36b) pattern with the verbal passive in (36a) in excluding a self-action interpretation, the standard diagnostic for VoiceP in Kratzer (1996, 2003), building on Baker, Johnson \& Roberts (1989). By contrast, derived nominals in (36c) allow a self-action interpretation indicating the lack of VoiceP. ${ }^{14}$

\footnotetext{
14 We agree with an anonymous reviewer that the derived nominal in (c) allows both for a self-action interpretation and an interpretation in which an external argument was responsible for the registration. The reviewer points out that a self-action interpretation has been identified for the verbal passive as well. To the extent that this holds, we might be able to attribute this to the ambiguity between the verbal and adjectival passive in English. The latter behaves as derived nominals do; see Alexiadou, Anagnostopoulou \& Schäfer (2015) for discussion of differences between verbal and adjectival passives and further references, see
} 
(36) a. The children were being registered.

i. $\quad * \mathrm{Th}=\mathrm{Ag}:$ The children registered themselves

ii. $\quad \mathrm{Th} \neq \mathrm{Ag}$ : The children were registered by someone

b. The report mentioned the painfully slow registering of the children.

$\mathrm{Th} \neq \mathrm{Ag} / * \mathrm{Th}=\mathrm{Ag}$

c. The report mentioned the painfully slow registration of the children.

$\mathrm{Th} \neq \mathrm{Ag} / \mathrm{Th}=\mathrm{Ag}$

\subsection{Summary}

In this section, we have reviewed four different arguments in favor of roots being able to take complements. Three of them involve the verbal domain, one involves the nominal domain. In all four cases, we have argued that the arguments are not conclusive and that the data are open to alternative implementations that do not require roots to take complements.

\section{Roots as adjuncts to the categorizing head}

Let us return to (5) from section 2, here repeated as (37).

$$
\text { a. }[\mathrm{v} v \sqrt{ } \mathrm{ROOT}]
$$

b. $\quad[\sqrt{\text { ROOT }} \mathrm{V} \sqrt{\mathrm{ROOT}}]$

We want to ensure that the grammar does not generate a structure where the root serves as the label of the categorized constituent. Technically, the only way to ensure that we never get

Alexiadou, Iordachioaia, Cano, Martin \& Schäfer (2014) for discussion of external arguments in nominalizations. 
(37b) is to propose that roots merge always as modifiers of/adjuncts to their categorizing head. Let us briefly address how this could work technically.

Chomsky (2004) distinguishes between Set Merge and Pair Merge. The former is ordinary merge, which creates an unordered set, whereas the latter is a type of merge that creates an ordered pair. Chomsky claims that adjunction corresponds to Pair Merge.
a. $\quad\{\alpha, \beta\}$
b. $\quad<\alpha, \beta>$

In cases of adjunction, the adjoined phrase $\gamma \mathrm{P}$ combines with another phrase $\delta \mathrm{P}$. Normally, $\delta \mathrm{P}$ projects the label (though see Donati 2006). In that sense, roots interact with categorizers in a similar way that adjuncts interact with the non-adjoined part of the structure. This would give us the following structure (using a fairly traditional depiction for adjunction structures). ${ }^{15}$

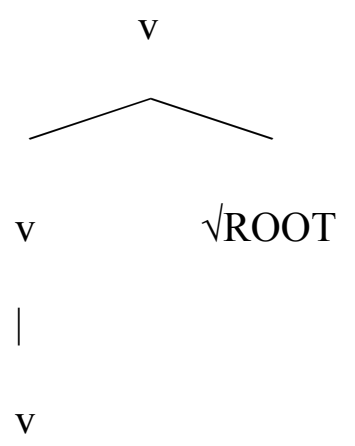

On this view, roots strictly speaking do not have to be categorized. This would predict that there are cases where roots can survive a derivation without being categorized. De Belder (in press) argues that this is exactly the case based on primary compounds in Dutch.

\footnotetext{
${ }^{15}$ Marantz (2013) puts forth several arguments in favor of the view that in English, roots always merge as modifiers of v. For reasons of space, we cannot review his arguments here.
} 


\section{Roots as complements or as adjuncts}

A different view holds that roots are merged with categorizing heads either as their complements or as modifiers. Perhaps the most prominent representative of this position is Embick (2004), see also Alexiadou \& Anagnostopoulou (2013), Alexiadou, Anagnostopoulou \& Schäfer (2015) for discussion. Embick, similarly to what is put forth in the work of Levin and Rappaport Hovav (2010), takes it that roots come in two guises; there are manner roots and state/result roots. These two types are integrated differently into the structural representation of the event. In Levin and Rappaport Hovav (2010), manner roots are integrated as modifiers of an event, while result roots are integrated as arguments of primitive predicates. In Embick's work, manner roots are merged as modifiers of categorizing heads whereas state/result roots are merged as complements of these heads, as shown in (40) below:

(40) a. modifiers of v, direct Merge

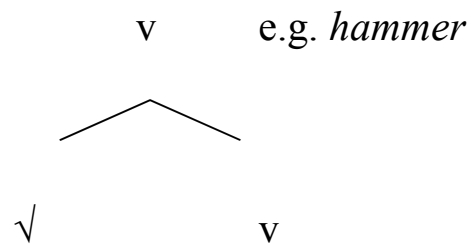

b. complements of $\mathrm{v}$

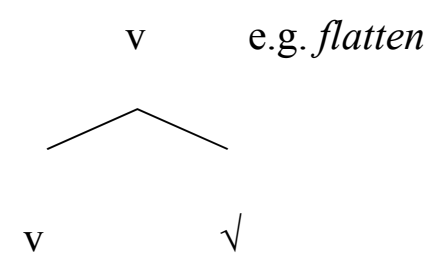

Embick suggests that direct merge has semantic consequences. It specifies the means component of the complex predicate. Implicitly, the type of merge is sensitive to the manner vs. result/state classification of roots. Manner roots merge as modifiers of v, state roots merge as complements of $\mathrm{v}$. The structure in (40a) can feed secondary resultative predication. In that case, the element that appears in the complement of $\mathrm{v}$ cannot be a bare root, see (41) below.

$$
\text { vP }
$$




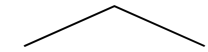

DP $\quad v^{6}$

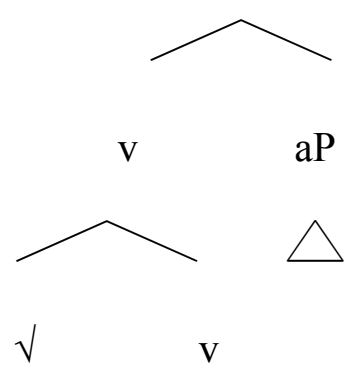

Embick argues that v's complement cannot be a bare Root when v has a Root merged with it, as in (41), because the Root in the complement position would be "uncategorized". That is, in (41) the complement of $\mathrm{v}$ is an aP. ${ }^{16}$ Direct merge applies to manner/instrument roots, and roots that can be so coerced, cf. Rossdeutscher (2011) and Marantz (2013). ${ }^{17}$

The above proposal implies that roots belong to ontological classes, which in turn influence the structural positions roots can occupy. However, as is evident from the structures in (40) above, in the absence of secondary resultative predication, direct Merge is practically indistinguishable from complement Merge. Furthermore, in view of the fact that several result roots can be coerced into manner interpretations is not clear what the argument in favor of (b) above is. Embick (2009) in fact introduces the notion of proxy state to describe the behavior of predicates such as break, which merge as modifiers of $\mathrm{v}$ but require an empty result state as

\footnotetext{
${ }^{16}$ Embick argues that the little $\mathrm{v}$ has a special feature which he labels FIENT for fientive, which is a type of BECOME-operator (Embick 2004: 366).

${ }^{17}$ The discussion in Embick raises the more general question, also raised by an anonymous reviewers, of whether or not roots need to be categorized to begin with, see our footnote 2 . It might very well be that some roots need not be categorized, leading perhaps to the formation of root compounds (see e.g. Bauke \& Roeper this volume, and Borer 2013). See also Alexiadou \& Iordachioaia (2015) for some discussion of compound formation in DM.
} 
their complement, which can sometimes be overt, e.g., break open. From this perspective then, structure ( $40 \mathrm{~b})$ seems to be restricted to a small subset of roots.

\section{Roots as special}

There is also a view in which roots are privileged because of the position which they occupy. There are two main implementations of this idea in the literature.

One implementation is due to Adger (2013). He argues that Self Merge (Guimarães 2000, Kayne 2010) is a fundamental operation which comes for "free" if one removes a stipulation in the standard definitions of Merge. A root is an entity which is able to undergo Self Merge: $\sqrt{ } \mathrm{DOG}$ would then yield $\{\sqrt{ } \mathrm{DOG}\}$. Adger also argues for a labeling algorithm which does not include roots in its domain. A crucial consequence of this is that a root cannot merge with any other object distinct from that root, which is to say that roots can never take complements. Once a root has undergone Self Merge, it can be labeled, but the label is inserted after the structure has been built, an important claim which Adger (2013) is devoted to defending.

A somewhat different implementation is due to De Belder and van Craenenbroeck (2015). They are concerned with a range of properties related to roots, most of which we will not have the space to discuss here. But one important question in their paper is whether roots are to be defined lexically or structurally. One way of illuminating this issue is to ask the following question: Can a functional vocabulary item (henceforth, FVI) be used as a root? De Belder and van Craenenbroeck say the following:

Suppose we want to use an FVI as a root. In an early insertion model this state of affairs is unformulable. The mere presence of grammatical features on a VI will cause the projection headed by this VI to be recognized as functional rather than lexical. As 
a result, FVIs can never head lexical projections. In the Late Insertion-model, however, there is no a priori ban on merging a particular type of VI in a root terminal node.

If roots are defined structurally, and given that the structural position is devoid of features, it is immaterial whether the VI realizing this position post-syntactically bears any grammatical features. Therefore, it is possible to use FVIs as a resting ground in order to distinguish between a lexical and a structural definition of a root. De Belder and van Craenenbroeck provide the following examples from Dutch.

(42) Ik heb het waarom van de zaak nooit begrepen.

I have the why of the case never understood

'I have never understood the motivation behind the case.'

(43) In een krantenartikel komt het wat/hoe/wie/waar

in a newspaper.article comes the what/how/who/where

altijd voor het waarom.

always before the why

'In a newspaper the what/how/who/where always precedes the why.'

De studenten jij-en onderling.

the students you-INFINITIVE amongst.one.another

'The students are on a first-name basis with each other.'

(45) Martha is mijn tweede $\boldsymbol{i k}$.

Martha is my second I

'Martha is my best friend.'

(46) Niets te maar-en! 
nothing to but-INFINITIVE

'Don’t object!'

(47) Paard is een het-woord.

horse is a the NEUTER.DEF-Word

'Paard takes a neuter article.'

These examples all illustrate the use of an FVI in what is a root position. A possible counterargument is to argue that these examples are exceptions. Rather, what is inserted in the root position is not an FVIs, but a root which happens to be homophonous with an FVI (De Belder and van Craenenbroeck 2015). However, this argument does not work. Consider the data in (48).

a. het getik van de klok the GE-tick of the clock 'the ticking of the clock.'

b. het gefluit van de vogeltjes the GE-whistle of the birds 'the whistling of the birds.'

In Dutch, there is a derivational word formation process which forms nouns referring to a pluractional event by means of ge-prefixation. This type of word formation productively allows FVIs to occur in root position. A range of examples are provided in (49). ${ }^{18}$

\footnotetext{
${ }^{18}$ It may be objected that De Belder and van Craenenbroeck (2015) do not fully justify that ge-actually attaches to the root, and not an element that is already categorized.
} 
(49) a. Ik hoefal dat ge-maar niet.

I need all that GE-but not

'I don't like those constant objections.'

b. Ik hoef al dat ge-alhoewel niet.

I need all that GE-although not

'I don't like those constant considerations.'

c. Ik hoefal dat ge-of niet.

I need all that GE-or not

'I don't like those constant alternatives.'

d. Ik hoef al dat ge-hé niet.

I need all that GE-PRT not

'I don't like the constant need for confirmation.'

e. Ik hoef al dat ge-waarom niet

I need all that GE-why not

'I don't like the constant need for justification.'

f. Ik hoef al dat ge-nooit niet

I need all that GE-never not

'I don't like the constant unwillingness.'

g. Ik hoef al dat ge-ik niet

I need all that GE-I not

'I don't like all this egocentricity.'

It is not very explanatory to assume that FVIs are systematically ambiguous between a root and a functional reading. De Belder and van Craenenbroeck instead take the data to show that FVIs can be used in root positions. Whether or not an item is a root or not cannot be due to 
inherent characteristics or properties of the item as such, rather, it depends on the structural position in which the element is merged.

Let us look at the technical implementation in De Belder and van Craenenbroeck (2015). They assume that Merge is inherently asymmetric (Jaspers 1998, Langendoen 2003, Cormack \& Smith 2005, Di Sciullo \& Isac 2008, Zwart 2009a, 2009b, 2011, Franco 2011, Osborne, Putnam \& Gross 2011) and that Pair Merge rather than Set Merge is the default (contrary to Chomsky 2004 and many others). They define Merge as follows.

\section{Unary Merge}

Merge selects a single subset from a resource (e.g. $\{\alpha\}$ ), includes it in the derivation under construction $(\delta)$, and yields an ordered pair (e.g. $<\{\alpha\}, \delta>$, assuming $\{\alpha\}$ projects).

They propose to take the definition in (50) as literally as possible. When an element $\{\alpha\}$ is the first one to be taken from the resource by Unary Merge, it is included into an empty derivation, i.e., the object under construction is the empty set Ø (see also Zwart 2011). The output of this instance of Merge is no different from any other: it yields an ordered pair, in this case $<\{\alpha\}, \varnothing>$.

De Belder and van Craenenbroeck argue for late insertion of all vocabulary items. ${ }^{19}$ This implies that the resource from which Merge draws contains only grammatical features. Moreover, roots play no role in the syntactic derivation and they are defined structurally. As a result, there are no features in the resource that refer to or anticipate the merger of a root. For the example they use as an illustration, the books, this means that the resource is a set containing a definiteness feature and a plural feature, i.e. $R=\{[+\mathrm{def}],[+\mathrm{pl}]\}$.

\footnotetext{
${ }^{19}$ See Embick (2000) for arguments in favor of early insertion of roots.
} 
Based on this resource, the derivation proceeds as follows. Unary Merge first selects the singleton containing the plural feature from $\mathrm{R}$ and merges it with the empty set. Given that the latter is featureless, it is the plural feature that projects.

(51)
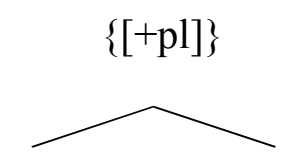

$\{[+\mathrm{pl}]\} \quad \varnothing$

In the next step, the definiteness feature is targeted by Merge. It too projects its own structure, yielding (52).

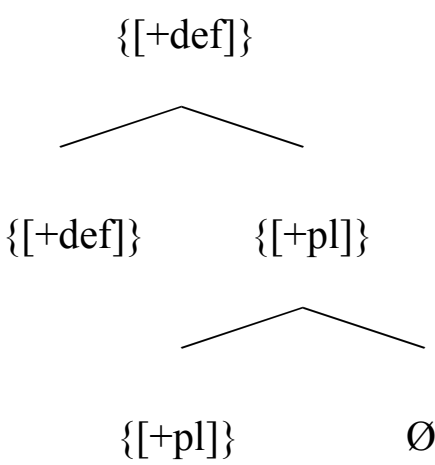

This concludes the syntactic derivation. The structure is handed over to PF, where Vocabulary Insertion (see Harley \& Noyer 1999 for discussion) applies. When confronted with the structure in (52), the following potential VIs occur:
a. $/ \delta ə / \leftrightarrow[+\mathrm{def}]$
b. $/ \mathrm{s} / \leftrightarrow[+\mathrm{pl}]$
c. $/$ buk $/ \leftrightarrow \varnothing$ 
The phonological exponents on the left-hand side of the equivalences in (53) are inserted into the terminal nodes of the structure. The derivation converges as the books.

On this view, $\varnothing$ can never project. This is equivalent to saying that roots cannot project (see Bauke \& Roeper this volume) and consequently, they are also acategorial. In De Belder and van Craenenbroeck's theory, it is always the set that merges with $\varnothing$ that projects and determines the category. $\varnothing$ will always appear lower than any functional material, which is an aspect that the analysis shares with Adger (2013). This yields the following.

\section{(54) One Derivational Workspace One Root (ODWOR)}

In every derivational workspace there is exactly one root, and for every root there is exactly one derivational workspace.

As (54) illustrates, this will yield different cycles than what most of the literature argues for (viz. phases of some sort).

One aspect of the De Belder and van Craenenbroeck analysis is that they do not account for the following two often-assumed claims: i) that roots have to be categorized, and ii) that the categorizer always seems to project. The first claim simply cannot be accounted for in their system, whereas the second property can be accounted for since it is the functional material above the $\varnothing$ that determines the labels of the ensuing structure.

\section{Discussion}

In this paper, we have presented the four different views on how roots are introduced into syntactic structures and categorized. (55) repeats (6) for expository convenience. 
(55) a. Roots are merged as complements of v (e.g., Bobaljik and Harley 2013, Harley 2014 and literature cited there).

b. Roots are merged as v modifiers (Marantz 2013).

c. Some roots are merged as v's modifier while others as v's complement (Embick 2004, 2010, Alexiadou \& Anagnostopoulou 2013)

d. Roots are inserted post-syntactically, thus they cannot take any complements or modify v (de Belder and van Craenenbroeck 2015).

We have pointed at arguments against and in favor of each of the alternatives. Based on Occam's razor, a unified way of introducing roots is to be preferred. (55b) is the only approach which derives endocentricity in the traditional sense, given that it entails that it is the label that always projects and serves as input to further applications of Merge. However, Embick's view also has certain advantages. For example, it accounts for why you cannot say (56b) but it is ok to say (56a). ${ }^{20}$

(56) a. colored dark

b. *blackened dark

The explanation is that (56a) roots can function as v modifiers whereas (56b) roots cannot. Note that the views in (55a), (55b) and (55d) do not have a straightforward way of accounting for this restriction since all instances of roots merging with a categorizer are identical. However, this view does face the challenges from section 3, where it was argued that roots

\footnotetext{
${ }^{20}$ An anonymous reviewer points out that strings such as mine was blackened darker than yours. Let us point out that this a comparative construction, which in our opinion enables a state/result root to be coerced into a manner reading, i.e. colored, as mentioned above in the context of (41).
} 
cannot take complements at all. What (c) argues, though, is that there has to be a distinction between roots being merged as modifiers and roots being merged in some other way. The latter may be as complements, although section 3 and the work cited there suggest otherwise. Thus we appear to be at an impasse, which future work hopefully will help resolve.

\section{Summary}

In this paper, we have discussed the possible structural configurations of categorization; that is, how roots come to be categorized in the syntax. We argued that there is a lot of evidence against roots taking complements, although the work discussed in section 5 provides another perspective. There are also problems with the other views presented. The view of roots as modifiers has the advantage that it derives the correct headedness of the structure, although it does not derive that roots often or always need to be categorized. Another view, that roots are introduced in a special way, is able to derive a lot of properties often attributed to roots, but it faces two main problems: i) it presents a special mechanism for introducing roots, i.e., it makes roots syntactically unique, ii) the view does not derive that roots often or always need to be categorized. We conclude that at present, there is not enough empirical evidence distinguishing the four views adequately and that more work needs to be done to tease them apart in order to provide a conclusive answer to what the structural configuration of categorization is.

\section{References}

Acquaviva, Paolo. 2009. Roots and lexicality in Distributed Morphology. In Alexandra Galani, Daniel Redinger \& Norman Yeo (eds.), York-Essex Morphology Meeting 5: Special Issue of York Working Papers in Linguistics, 1-21. York: University of York, Department of Language and Linguistic Science. 
Adger, David. 2013. The Syntax of Substance. Cambridge, MA: MIT Press.

Alexiadou. Artemis. 2001. Functional structure in nominals. Amsterdam: John Benjamins.

Alexiadou, Artemis. 2009. On the role of syntactic locality in morphological processes: the case of (Greek) nominals. In Anastasia Giannakidou \& Monika Rathert (eds.), Quantification, Definiteness, and Nominalization, 253-280. Oxford: Oxford University Press.

Alexiadou, Artemis. 2010a. Nominalizations: a probe into the architecture of grammar. Part I: the nominalization puzzle. Language and Linguistics Compass 4. 496-511.

Alexiadou, Artemis. 2010b. Nominalizations: a probe into the architecture of grammar. Part II: the aspectual properties of nominalizations, and the lexicon vs. syntax debate. Language and Linguistics Compass 4. 512-523.

Alexiadou, Artemis. 2014. Roots don't take complements. Theoretical Linguistics 40. 287297.

Alexiadou, Artemis \& Elena Anagnostopoulou. 2013. Manner vs. Result Complementarity in Verbal Alternations: A View from the Clear-Alternation. In Stefan Keine and Shayne Sloggett (eds.), Proceedings of the Forty-Second Annual Meeting of the North East Linguistic Society, 39-52. University of Massachusetts, Amherst: GSLA.

Alexiadou, Artemis, Elena Anagnostopoulou \& Florian Schäfer. 2006. In Mara Frascarelli (ed.), The Properties of Anticausatives Cross-linguistically. Phases of Interpretation, 187212. Berlin: Mouton de Gruyter.

Alexiadou, Artemis, Elena Anagnostopoulou \& Florian Schäfer. 2015. External Arguments in Transitivity Alternations. A Layering Approach. Oxford: Oxford University Press. Alexiadou, Artemis \& Gianina Iordachioaia. 2015. Idiomaticity and compositionality in deverbal compounds. Paper presented at BCGL 8, Brussels. http://www.crissp.be/events/bcgl8/bcgl8-program/. 
Alexiadou, Artemis \& Kirsten Gengel. 2011. Classifiers as morphosyntactic licensors of NP ellipsis: English vs. Romance. In Suzi Lima, Kevin Mullin \& Brian Smith (eds.), Proceedings of the Thirty-Ninth Annual Meeting of the North East Linguistic Society, 1528. University of Massachusetts, Amherst: GSLA.

Alexiadou, Artemis \& Jane Grimshaw. 2008. Verbs, nouns and affixation. In Florian Schäfer (ed.), SinSpec 1: Working Papers of the SFB 732, 1-16. Stuttgart: Universität Stuttgart.

Alexiadou, Artemis, Liliane Haegeman \& Melita Stavrou. 2007. Noun Phrase in the Generative Perspective. Berlin: Mouton de Gruyter.

Alexiadou, Artemis, Gianina Iordachioia, Mariangeles Cano, Fabienne Martin \& Florian Schäfer. 2013. The realization of external arguments in nominalizations. Journal of Comparative Germanic Linguistics 16: 73-95.

Anagnostopoulou, Elena and Yota Samioti. 2014. Domains within Words and their meanings: a case study. The Syntax of Roots and the Roots of Syntax, Artemis Alexiadou, Hagit Borer and Florian Schäfer (eds.), 81-111. Oxford: Oxford University Press.

Arad, Maya. 2003. Locality constraints on the interpretation of roots: The case of Hebrew denominal verbs. Natural Language and Linguistic Theory 21.737-778.

Arad, Maya. 2005. Roots and patterns: Hebrew morphosyntax. Dordrecht: Springer.

Bobaljik, Jonathan D. 2012. Universals in Comparative Morphology: Suppletion, superlatives, and the structure of words. Cambridge, MA: The MIT Press.

Bobaljik, Jonathan D. and Heidi Harley. 2013. Suppletion is Local: Evidence from Hiaki. Ms., University of Connecticut and University of Arizona.

Borer, Hagit. 2005a. Structuring Sense: In Name Only. Oxford: Oxford University Press. Borer, Hagit. 2005b. Structuring Sense: The Normal Course of Events. Oxford: Oxford University Press.

Borer, Hagit. 2013. Structuring Sense: Taking Form. Oxford: Oxford University Press. 
Bowers, John. 1993. The Syntax of Predication. Linguistic Inquiry 24. 591-656.

Bowers, John. 2010. Arguments as Relations. Cambridge, MA: MIT Press.

Cinque, Guglielmo. 1994. On the evidence for partial N-Movement in the Romance DP. In Guglielmo Cinque, Jan Koster, Jean-Yves Pollock, Luigi Rizzi \& Rafaella Zanuttini (eds.), Paths Towards Universal Grammar, 85-110. Washington (D.C): Georgetown University Press.

Chomsky, Noam. 1995. The Minimalist Program. Cambridge, MA: MIT Press.

Chomsky, Noam. 2004. Beyond Explanatory Adequacy. In Adriana Belletti (ed.), Structures and Beyond: The Cartography of Syntactic Structures, 104-131. Oxford: Oxford University Press.

De Belder, Marijke. 2011. Roots and affixes: eliminating lexical categories from syntax. Doctoral dissertation, University of Utrecht.

De Belder, Marijke. 2013. Collective mass affixes: when derivation restricts functional structure. Lingua 126. 32-50.

De Belder, Marijke. In press. The root and nothing but the root: Primary compounds in Dutch. Syntax.

De Belder, Marijke \& Jeroen van Craenenbroeck. 2015. How to merge a root? Linguistic Inquiry 46.

Di Sciullo, Anna Marie \& Daniela Isac. 2008. The asymmetry of merge. Biolinguistics 2. 260290.

Donati, Caterina. 2006. On wh head movement. In Lisa Cheng \& Norbert Corver (eds.), Wh Moving On, 21-46. Cambridge, MA: MIT Press.

Embick, David. 2000. Features, Syntax, and Categories in the Latin Perfect. Linguistic Inquiry 31. 185-230. 
Embick, David. 2004. On the structure of resultative participles in English. Linguistic Inquiry 35. 355-392.

Embick, David. 2009. Roots, States, and Stative Passives. Paper presented at the Roots workshop, University of Stuttgart, June 2009.

Embick, David. 2010. Localism vs. Globalism in Morphology and Phonology. Cambridge MA: MIT Press.

Embick, David \& Morris Halle. 2005. On the Status of Stems in Morphological Theory. In Twan Geerts, Ivo van Ginneken \& Haike Jacobs (eds.), Romance Languages and Linguistic Theory 2003: Selected Papers from Going Romance 2003, Nijmegen, 20-22 November, 37-62. Amsterdam: John Benjamins.

Embick, David \& Alec Marantz. 2008. Architecture and Blocking. Linguistic Inquiry 29. 153.

Folli, Raffaella \& Heidi Harley. 2005. Flavors of v: Consuming results in Italian and English. In Paula Kempchinsky \& Roumyana Slabakova (eds.), Aspectual inquiries, 95-120. Dordrecht: Springer.

Folli, Raffaella \& Heidi Harley. 2007. Causation, obligation, and argument structure: On the nature of little v. Linguistic Inquiry 38. 197-238.

Franco, Ludovico. 2011. The strict asymmetry of Merge. Ms., Università Ca'Foscari, Venice.

Grimshaw, Jane. 1990. Argument Structure. Cambridge, MA: MIT Press.

Grimstad, Maren Berg, Terje Lohndal \& Tor Anders Åfarli. 2014. Language mixing and exoskeletal theory: A case study of word-internal mixing in American Norwegian. Nordlyd 41: $213-237$.

Guimarães, Maximiliano. 2000. In defense of vacuous projections in Bare Phrase Structure. University of Maryland Working Papers in Linguistics 9. 90-115. 
Hale, Kenneth \& Samuel Jay Keyser. 1993. On argument structure and the lexical expression of syntactic relations. In Kenneth Hale and Samuel Jay Keyser (eds.), The View from Building 20: Essays in Linguistics in Honor of Sylvain Bromberger, 53-109. Cambridge, MA: MIT Press.

Hale, Kenneth \& Samuel Jay Keyser. 2002. Prolegomenon to a Theory of Argument Structure. Cambridge, MA: MIT Press.

Halle, Morris \& Alec Marantz. 1993. Distributed Morphology and the pieces of inflection. In Kenneth Hale and Samuel Jay Keyser (eds.), The View from Building 20: Essays in Linguistics in Honor of Sylvain Bromberger, 111-176. Cambridge, MA: MIT Press.

Harley, Heidi. 1995. Subjects, Events and Licensing. Doctoral dissertation, MIT.

Harley, Heidi \& Rolf Noyer. 1999. Distributed Morphology: State-of-the-art article. Glot International 4. 3-9.

Harley, Heidi. 2005a. How do verbs take their names? Denominal verbs, manner incorporation and the ontology of roots in English. In Nomi Erteschik-Shir \& Tova Rapoport (eds.), The Syntax of Aspect, 42-64. Oxford: Oxford University Press.

Harley, Heidi. 2005b. Bare Phrase Structure, A-categorial Roots, One-replacement and unaccusativity. In Yaroslav Gorbachov \& Andrew Nevins (eds.), Harvard Working Papers in Linguistics 11, 59-78. Cambridge: Harvard University, Department of Linguistics.

Harley, Heidi. 2014. On the Identity of Roots. Theoretical Linguistics 40. 225-276.

Harley, Heidi and Rolf Noyer. 2000. Licensing in the non-lexicalist lexicon. In Bert Peeters (ed.), The Lexicon/Encyclopedia Interface, 349-374. Amsterdam: Elsevier.

Harley, Heidi \& Megan Schildmier Stone. 2013. The 'No Agent Idioms’ Hypothesis. In Raffaella Folli, Christina Sevdali \& Robert Truswell (eds.), Syntax and Its Limits, 251-274. Oxford: Oxford University Press. 
Herburger, Elena. 2000. What Counts: Focus and Quantification. Cambridge, MA: MIT Press.

Horvath, Julia \& Tal Siloni. 2002. Against the little-v hypothesis. Rivista di Grammatica Generativa 27. 107-122.

Jackendoff, Ray. 1977. X-bar Syntax: A Study of Phrase Structure. Cambridge, MA: MIT Press.

Jaspers, Danny. 1998. Categories and recursion. Journal of Applied Linguistics 12. 81-112.

Jeong, Youngmi. 2007. Applicatives: Structure and Interpretation from a Minimalist Perspective. Amsterdam: John Benjamins.

Kayne, Richard S. 2010. Antisymmetry and the lexicon. In Anna Maria Di Sciullo \& Cedric Boeckx (eds.), The Biolinguistic Enterprise, 329-353. Oxford: Oxford University Press.

Kratzer, Angelika. 1996. Severing the external argument from its verb. In Johan Rooryck \& Laurie Zaring (eds.), Phrase structure and the lexicon, 109-137. Dordrecht: Kluwer.

Kratzer, Angelika. 2003. The event argument and the semantics of verbs. Ms., University of Massachusetts, Amherst.

Langendoen, Terence D. 2003. Merge. In Andrew Carnie, Heidi Harley \& Mary Willie (eds.), Formal approaches to function in grammar: In honor of Eliose Jelinek, 307-318. Amsterdam: John Benjamins.

Lechner, Winfried, Giorgos Spathas, Artemis Alexiadou \& Elena Anagnostopoulou. 2015. On deriving the typology of repetition and restitution. Paper prsented at GLOW 38, Paris. https://sites.google.com/site/2015glow/home/programme.

Lin, Tzong-Hong. 2001. Light verb syntax and the theory of phrase structure. Doctoral dissertation, University of California, Irvine.

Lohndal, Terje. 2012. Without Specifiers: Phrase Structure and Events. Doctoral dissertation, University of Maryland. 
Lohndal, Terje. 2014. Phrase Structure and Argument Structure: A Case Study of the Syntax Semantics Interface. Oxford: Oxford University Press.

Marantz, Alec. 1984. On the Nature of Grammatical Relations. Cambridge, MA: MIT Press.

Marantz, Alec. 1997. No escape from Syntax: Don't try morphological analysis in the privacy of your own lexicon. In A. Dimitriadis, L. Siegel, C. Surek-Clark \& A. Williams (eds.), University of Pennsylvania Working Papers in Linguistics, 201-225. Philadelphia: University of Philadelphia.

Marantz, Alec. 2005. Objects out of the lexicon: Objects as events. Ms., MIT.

Marantz, Alec. 2013. Locating the Verbal Root. Talk given at the 25th Scandinavian Conference of Linguistics, University of Iceland, Reykjavik.

Merchant, Jason. 2013. Voice and Ellipsis. Linguistic Inquiry 44. 77-108.

Newmeyer, Frederick J. 2008. Current Challenges to the Lexicalist Hypothesis: An Overview and a Critique. In Will Lewis, Simin Karimi, Heidi Harley, \& Scott Farrar (eds.), Time and Again: Papers in Honor of D. Terence Langendoen, 91-117. Amsterdam: John Benjamins.

Nunberg, Geoffrey, Ivan A. Sag \& Thomas Wasow. 1994. Idioms. Language 70. 491-538.

Osborne, Timothy, Michael Putnam \& Thomas M. Gross. 2011. Bare phrase structure, label less trees, and specifier-less syntax. Is Minimalism becoming a dependency grammar? The Linguistic Review 28. 315-364.

Pesetsky, David. 1995. Zero Syntax. Cambridge, MA: MIT Press.

Pustejovsky, James. 1991. The syntax of event structure. Cognition 41. 47-82.

Pylkkänen, Liina. 2008. Introducing Arguments. Cambridge, MA: MIT Press.

Radkevich, Nina. 2010. On Location: The structure of case and adpositions. Doctoral dissertation, University of Connecticut.

Ramchand, Gillian. 2008. Verb Meaning and the Lexicon: A First Phase Syntax. Cambridge: Cambridge University Press. 
Rappaport Hovav, Malka \& Beth Levin. 2010. Reflections on Manner/Result

Complementarity. In Edith Doron, Malka Rappaport Hovav \& Ivy Sichel (eds.), Syntax, Lexical Semantics, and Event Structure, 21-38. Oxford: Oxford University Press.

Rossdeutscher, Antje. 2011. Particle verbs and prefix verbs in German: Linking theory versus word-syntax. Leuvense Bijdragen 97. 1-53.

Roy, Isabelle. 2010. Deadjectival nominalizations and the structure of the adjective. In Artemis Alexiadou \& Monika Rathert (eds.), The syntax of nominalizations across languages and frameworks, 129-158. Berlin: Mouton de Gruyter.

Schäfer, Florian. 2008. The Syntax of (Anti)Causatives: External Arguments in Change-ofState Contexts. Amsterdam: John Benjamins.

Schäfer, Florian. 2012. Two types of external argument licensing: The case of causers. Studia Linguistica 66. 128-180.

Schein, Barry. 1993. Plurals and Events. Cambridge, MA: MIT Press.

Schein, Barry. 2003. Adverbial, descriptive reciprocals. Philosophical Perspectives 17. 333367.

Speas, Margaret J. 1990. Phrase Structure in Natural Language. Dordrecht: Kluwer. von Stechow, Arnim. 1996. The different readings of wieder 'again': A structural account. Journal of Semantics 13. 87-138.

Tenny, Carol. 1987. Grammaticalizing aspect and affectedness. Doctoral dissertation, MIT. Tenny, Carol. 1994. Aspectual Roles and The Syntax-Semantics Interface. Dordrecht: Kluwer. Wechlser, Stephen. 1990. Accomplishments and the Prefix re-. Proceedings of the North Eastern Linguistic Society XIX, Juli Carter and Rose-Marie Dechaine (eds.), 419-434. Zwart, Jan-Wouter. 2009a. Uncharted territory? Towards a non-cartographic account of Germanic syntax. In Artemis Alexiadou, Jorge Hankamer, Thomas McFadden, Justin 
Nuger \& Florian Schäfer (eds.), Advances in Comparative Germanic Syntax, 59-84.

Amsterdam: John Benjamins.

Zwart, Jan Wouter. 2009b. Prospects for top-down derivation. Catalan Journal of Linguistics 8. 161-187.

Zwart, Jan-Wouter. 2011. Structure and order: asymmetric merge. In Cedric Boeckx (ed.), The Oxford Handbook of Linguistic Minimalism, 96-118. Oxford: Oxford University Press. 